\title{
La vivienda unifamiliar, fenómeno característico de la ciudad dispersa. Contrastes sectoriales en la aglomeración urbana de Madrid
}

\author{
José Miguel Santos Preciado \\ Departamento de Geografía. Universidad Nacional de Educación a Distancia \\ jsantos@geo.uned.es \\ Francisco Javier GARCÍA LÁZARO \\ ETSI Topografía, Geodesia y Cartografía \\ Universidad Politécnica de Madrid
}

Recibido: 15 de Junio de 2011

Enviado a evaluar: 10 de Febrero de 2011

Aceptado: 24 de Abril de 2012

\section{RESUMEN}

Las aglomeraciones urbanas occidentales han sufrido, durante los últimos años, una profunda transformación, desde el primitivo modelo del área metropolitana al de ciudad dispersa actual. Uno de los rasgos definitorios de este nuevo modelo urbano es la aparición, en las periferias de la ciudad, de un tejido residencial de baja densidad, con predominio de la vivienda unifamiliar, que conlleva una ocupación ilimitada del suelo urbanizable y un costo medioambiental sin precedentes.

En nuestro país, el cambio ha tenido lugar, desigualmente, de manera más substancial en las grandes urbes. El trabajo que presentamos, intenta, a partir de las bases de datos cartográficas del catastro, en formato digital, y la utilización de los Sistemas de Información Geográfica, como herramienta de gestión territorial, cuantificar el proceso de transformación urbana de la Comunidad de Madrid, comprobando los fuertes contrastes residenciales, respecto al binomio compacidad-dispersión, que existe entre los sectores sur y oeste metropolitanos.

Palabras clave: vivienda unifamiliar, residencia de baja densidad, ciudad dispersa, Sistemas de Información Geográfica, parcela catastral. 


\title{
Single-family homes, a characteristic phenomenon of the scattered city. Sectorial contrasts in the urban agglomeration of Madrid
}

\begin{abstract}
Conurbations in western countries have undergone a deep transformation during the last years, evolving from the primitive metropolitan-area model to the current pattern of scattered cities. One of the defining characteristics of this new urban model is the spreading of low population density residential areas over the peripheries of cities, with prevalence of single family-dwellings. This results in an unlimited occupation of developable land such that environmental costs are much higher than hitherto.

In Spain, this change has happened in a differentiate manner, more significantly in the great urban centres. This work is an endeavour of quantifying the process of urban transformation over Madrid's region by using digital cadastral databases and geographic information systems, to assess the contrast between southern and western metropolitan sectors regarding the compactness-dispersion dichotomy.
\end{abstract}

Key words: single-family dwelling, low density residential area, scattered city, Geographic Information Systems, cadastral lot.

\section{Maison individuelle, phénomène caractéristique de la ville dispersée. Contrastes sectoriaux de l'agglomération urbaine de Madrid}

\begin{abstract}
RÉSUMÉ
Pendant les dernières années, les agglomérations urbaines aux pays occidentaux ont expérimenté une transformation du primitif model des zones métropolitaines vers l'actuel de la cité disperse. Un des traits définitoires du neuf model est l'apparition, a la périphérie des cités, d'un tissu résidentiel à bas densité, où prédominent les maisons unifamiliales, ce que comporte une occupation illimitée du sol urbanisable et aussi des couts environnementaux sans précédents.

Le change à L'Espagne a succédé inégalement, d'une façon plus significative aux grands centres urbains. Le travail que nous présentons intente quantifier le procès de transformation urbaine de la Région de Madrid a partir des bases de données géographiques cadastrales digitalisés et de l'utilisation des systèmes d'information géographique, en vérifiant le contraste qu'il y existe entre les secteurs métropolitains du sud et de l'ouest par rapport au binôme compacité - dispersion.
\end{abstract}

Mots-clés:maison unifamiliale, sol résidentiel à bas densité, cité disperse, Systèmes d'information géographique, parcelle cadastrale.

\section{LA CIUDAD DISPERSA: UNA NUEVA FORMA DE LA ORGANIZACIÓN URBANA ACTUAL}

La reciente dinámica de la ciudad obedece, en realidad, al nuevo papel asignado a los centros urbanos en la organización económica mundial. El carácter global de las relaciones económicas ha redundado en la configuración de un espacio mundial de acumulación, en el que los capitales se valorizan en un número creciente 
de lugares y de actividades. En este espacio, se ha afirmado una nueva arquitectura productiva, basada en un número creciente de grandes empresas de cobertura multinacional, organizadas en red, que han pasado a constituir los actores principales de la nueva dinámica económica.

La organización territorial de esta nueva realidad productiva varía según el nivel de escala considerado. A nivel interurbano, un número creciente de aglomeraciones urbanas destacan como los lugares preferidos para la localización de los nodos principales de dichas redes. "Con ello, se ha producido una reterritorialización y reescalamiento de la economía global, donde algunas ciudades juegan un papel estratégico dominante." (Mattos, 2004).

A nivel intraurbano, "los recientes procesos de difusión reticular de la ciudad están dando origen a periferias urbanas de un tipo muy distinto de aquellas que se habían formado en Europa desde la revolución industrial hasta la década de 1960" (Dematteis, 1998). Este nuevo modelo urbano cabe considerarlo muy alejado del área metropolitana planetaria y equilibrada, con núcleos compactos, agregados e integrados, y más cercano al modelo de ciudad dispersa, motivado por los procesos de innovación tecnológica, por la universalización del acceso del automóvil y por el abaratamiento del coste del transporte. "Una nueva ciudad que ha destruido la idea de centro, típica del modelo metropolitano monocéntrico, por un infinito urbanizado de espacios anónimos, difuminando cada vez más los límites entre campo y ciudad" (León Rodríguez, 2008).

En la construcción del espacio urbanizado contemporáneo de este nuevo tipo de ciudad, desde un punto de vista físico y urbanístico, se detectan los siguientes síntomas (Gaja i Diaz, 2004):

1. Un creciente consumo de suelo, sin crecimiento demográfico;

2. La constitución de estructuras policéntricas, reticuladas o malladas, superando las antiguas estructuras metropolitanas monocéntricas o con un núcleo principal;

3. La primacía del espacio de las comunicaciones;

4. La aparición de una nueva periferia, con abundante empleo terciario, frente a la tradicional periferia metropolitana, inicialmente sólo industrial, y después residencial y comercial;

5. La pérdida de densidad y de la continuidad espacial;

La consecuencia básica de este nuevo modelo es que la periferia no constituye ya un espacio fácilmente identificable en la misma medida en que lo era anteriormente. "Ahora, en primer lugar, abarca una superficie mucho más extensa que la de los núcleos centrales y sus periferias primeras. Pero, sobre todo, en segundo lugar, se trata de un espacio que se caracteriza por su confusión formal y su desarticulación territorial, en la que los usos urbanos o, si se quiere, espacios construidos, se entremezclan con los rurales a la vez que aquellos se combinan entre sí, la mayor parte de las veces sin demasiado acierto, en una amalgama de funciones y tipologías formales" (Feria Toribio, 1999). 


\section{LA VIVIENDA UNIFAMILIAR, UNO DE LOS RASGOS BÁSICOS DE LA CIUDAD DISPERSA}

Una de las características que mejor definen el nuevo modelo de la ciudad dispersa es la localización y morfología de la función residencial. La suburbanización de la vivienda está teniendo lugar con claro predominio de las bajas densidades y la tipología unifamiliar. En el mundo anglosajón, derivado de su propia cultura urbanística, la oferta residencial de la periferia sigue mayoritariamente, desde hace tiempo, este modelo extensivo. Esta realidad también se está imponiendo en muchas de las ciudades europeas, incluso en las mediterráneas, donde los tradicionales patrones de ubicación, ofrecidos en etapas anteriores, estaban representados por actuaciones urbanísticas multifamiliares de alta densidad de ocupación del suelo.

En realidad, esa vocación extensiva del tejido residencial urbano no constituye un fenómeno nuevo. La cuestión de cómo se había de realizar la expansión urbana de la ciudad es un debate de comienzos del siglo XX. "La contraposición entre la casa unifamiliar y los bloques elevados en altura aparece ya, explícitamente, en el urbanismo desde los años veinte del pasado siglo. Continúa, por tanto, siendo uno de los dilemas esenciales del desarrollo de la ciudad actual: la dispersión hacia el exterior con predominio de viviendas unifamiliares y la ocupación ilimitada del espacio, o la concentración en bloques cada vez más elevados o rascacielos, por otro" (Capel, 2003).

Veamos, más detenidamente, los factores explicativos, así como alguno de los rasgos que hacen posible diferenciar, hoy en día, el modelo extensivo residencial de la ciudad dispersa respecto al del modelo tradicional metropolitano compacto.

\section{1. LA ACENTUACIÓN DEL FENÓMENO DE LA SUBURBANIZACIÓN RESIDENCIAL DE BAJA DENSIDAD EN EL MODELO DE LA CIUDAD DISPERSA: PRINCIPALES FACTORES DE SU DESARROLLO}

El incremento del impacto de la vivienda unifamiliar en el paisaje urbano de la ciudad actual tiene que ver con múltiples factores, derivados, tanto de las posibilidades que ofrece la tecnología actual en el desarrollo de los medios de transporte y las comunicaciones, como del incremento del nivel de vida de las sociedades occidentales y la aceptación de esta nueva forma de vida por las clases medias.

La tradición de la vivienda unifamiliar ha estado profundamente arraigada en el mundo anglosajón. Ya Peter Hall, en una fecha tan temprana como 1965, valoraba muy positivamente esa forma de desarrollo urbano: "una densidad baja de características uniformes tiene muchas más ventajas que las que podrían pensar muchos urbanistas europeos: aumenta la flexibilidad, hace posible que el ciudadano elija el tipo de su vivienda, reduce la congestión y aumenta la facilidad de acceso" (Hall, 1965). De todas maneras, el autor era también consciente de sus desventajas y señalaba algunas: "este sistema urbanístico es caro, implica la ne- 
cesidad de viajes largos y no facilita grandemente los contactos accidentales entre los diferentes miembros de la comunidad y entre éstos y los problemas reales". El veredicto final era que en países de esa tradición resulta totalmente claro que una mayoría abrumadora de la población metropolitana, suponiendo que pueda ejercitar su derecho de elección, optaría por una vivienda unifamiliar, incluida en una zona edificada a media e incluso baja densidad (Capel, 2003). Sin embargo, podemos afirmar hoy en día que "la preferencia por el tipo de vida suburbano anglosajón ha traspasado todas las fronteras y que el deseo de las familias de vivir en una casa unifamiliar amplia en el campo, rodeada de amplios espacios verdes $\mathrm{y}$ en un medio ambiente tranquilo, pero bien comunicada por autopista con la ciudad, se ha convertido en un estereotipo internacional" (Ferrás Sexto, 2000).

Independientemente de las razones de las personas para vivir en un entorno de estas características, lo cierto es que las actuales formas de urbanización dispersa se producen "porque las condiciones socioeconómicas y las normativas políticas hacen posible que exista suelo disponible y que, para determinados grupos sociales, sea más rentable económicamente el uso urbano de ese suelo que dejarlo como espacio agrícola o como zona verde. Asimismo, todo esto sucede porque hay una considerable parte de la población con unos hábitos culturales o de vida que disponen de unos niveles de ingresos que les permiten o predisponen a llevar a cabo asentamientos de tipo disperso y desconcentrado" (Entrena Durán, 2004). Esta dispersión urbana, restringida hasta hace poco al área de influencia de una gran ciudad, ha ampliado su radio de acción, merced a la posibilidad de disponer en las zonas rurales de las mismas comodidades que ofrece la ciudad, tales como las redes de electricidad, el teléfono y el agua corriente (Dupuy, 1995). Todos estos factores, unidos al creciente deterioro de las condiciones de vida en las saturadas urbes, contribuyen a que aumente el atractivo de vivir en localidades periféricas de las ciudades cada vez más alejadas del centro de ellas.

Otro de los factores que han influido decisivamente en el triunfo de la urbanización residencial de baja densidad ha sido el desarrollo experimentado por los medios de comunicación y el crecimiento exponencial de las infraestructuras viarias en la gran ciudad. La dependencia de los habitantes de este tipo de urbanización periférica del vehículo privado es prácticamente total. Por este motivo, la generalización del modo de vida suburbano de tipo extensivo a la sociedad europea ha tenido mucho que ver con el desarrollo del automóvil privado y su acceso masivo al disfrute de este bien que ha terminado por convertirse en esencial. Así mismo, las redes de comunicación viaria y de transporte actualmente existentes han acrecentado considerablemente la capacidad de movilidad de los ciudadanos, que ahora disponen de mejores infraestructuras viarias y tienen más recursos económicos y medios de transporte públicos o privados para desplazarse diariamente, a lo largo de distancias considerablemente mayores que en el pasado, desde su lugar de residencia al de trabajo y viceversa. 


\section{2. LAS CARACTERÍSTICAS ESTRUCTURALES Y MORFOLÓGICAS DE LAS NUEVAS PERIFERIAS RESIDENCIALES}

Los principales rasgos estructurales y morfológicos de este nuevo tejido urbano, que lo diferencian claramente del período anterior serían los siguientes:

1. La generalización de este modo de vida, asociado a la vivienda unifamiliar, a todos los grupos sociales. La vivienda unifamiliar y la baja densidad habían sido consustanciales, al menos en las ciudades mediterráneas, a las clases sociales de mayor nivel de renta, mientras que en el momento presente (sobre todo a partir de 1980) se dirigen al conjunto de las clases medias y medias-bajas, lo que supone la expansión de la nueva morfología urbana residencial a todos los ámbitos de la periferia metropolitana, creando paisajes urbanos aparentemente semejantes, pero a través de una amplia variedad de tipologías edificatorias, desde viviendas aisladas de lujo, de gran superficie de parcela y calidad arquitectónica, hasta viviendas adosadas de ínfima calidad de construcción y escaso valor ecológico del entorno en donde se hallan situadas.

2. El segundo aspecto a considerar está relacionado con la densidad de ocupación del suelo por habitante. Si se tienen en cuenta las diferencias morfológicas de la edificación, un hecho trascendental es el mayor consumo directo de suelo que la vivienda unifamiliar representa en relación con la plurifamiliar o en bloque. Éste es un elemento importante a la hora de valorar el consumo de suelo metropolitano de las tres últimas décadas, en nuestro país, sobre todo si se tiene en cuenta que la mayor parte del nuevo suelo urbanizado se ha producido, consolidando sectores de edificación de baja densidad con un débil incremento de los efectivos demográficos. Así, "únicamente en el periodo 1987-2000, se ha urbanizado una superficie que equivale a casi un tercio de todo lo que se urbanizó en los siglos anteriores; mientras que la población creció un 4,6\%, el número de viviendas se incrementó en torno a un 22\%" (Molini y Salgado, 2010).

3. En tercer lugar, los nuevos desarrollos residenciales manifiestan, además, un carácter disperso y fragmentado. Sería necesario diferenciar el concepto de baja densidad del de dispersión propiamente dicha. Así, la baja densidad aludiría a asentamientos residenciales que, en relación con su superficie, estarían por debajo de la media de situaciones análogas. Por dispersión, en cambio, entendemos la valoración de la posición relativa en el espacio de los asentamientos, fragmentos, o elementos individuales entre sí, que generan una estructura espacial discontinua (Font, 2007). De esta manera, al margen de la mayor o menor densidad de ocupación del suelo, las áreas residenciales se situarían de forma interrumpida, dejando espacios intersticiales entre sí, de lo que resultaría un paisaje fragmentado y disperso.

4. En cuarto lugar, deberíamos considerar las posibles diferencias sectoriales existentes dentro de una misma aglomeración urbana. Esta situación se ha puesto de manifiesto de manera evidente (como tendremos ocasión de comprobar) en las principales áreas urbanas españolas, como en el área metropolitana madrileña, objetivo fundamental de nuestra investigación.

5. El modelo metropolitano clásico, característico de la etapa fordista, establecía un esquema exclusivamente polarizado por un núcleo central, donde se hallaban ubicadas las principales funciones urbanas terciarias y una periferia dominada por las funciones 
residencial e industrial. Por contraste, el nuevo modelo de ciudad puede ser definido como policéntrico, con la aparición de nuevas centralidades en la periferia, que acercarían determinados servicios y equipamientos (empleos de oficinas y terciario en general, centros comerciales, centros de ocio, etc.) a los residentes en el extrarradio de la ciudad. Existen trabajos recientes, de naturaleza cuantitativa (Muñiz et al., 2006), donde el policentrismo se incluye como una de las dimensiones de la dispersión. Significa ello que el fenómeno de la dispersión en el territorio tiene lugar en fases, de manera, que al gradiente de dispersión más puro del CBD de una ciudad, se sobrepone la estructura multicéntrica, para originar nuevos gradientes a considerar con el anterior (figura 1).

Figura 1. Organización de la densidad residencial de la ciudad en un sistema monocéntrico y en otro policéntrico
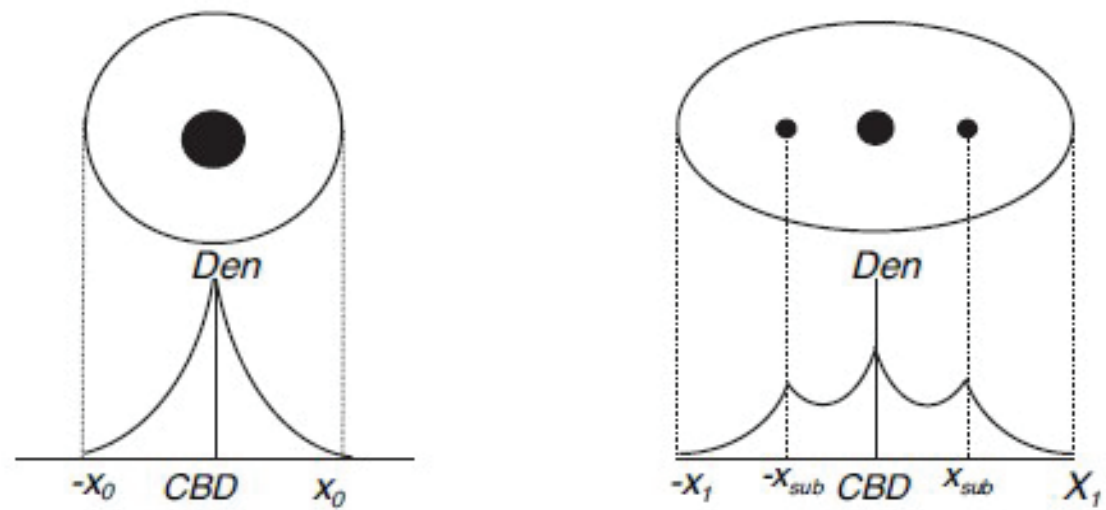

6. Finalmente, en esta realidad urbana, el tejido residencial de baja densidad, se estaría extendiendo a través de unas nuevas periferias de carácter heterogéneo, sin unas pautas claras de diferenciación de los usos del suelo allí representados. En tales áreas "se incluirían, en discontinuidad espacial, zonas construidas de diversa densidad, espacios abiertos, actividades agrícolas, reservas naturales, extensiones residenciales y concentraciones de servicios y actividades industriales, repartidos a lo largo de ejes de transporte constituidos por autopistas y sistemas de transporte público. No existiría una verdadera división en zonas, ya que los lugares de trabajo y las áreas residenciales y comerciales estarían dispersos en varias direcciones" (Castells, 2001).

\section{CONTRASTES DE LA ESTRUCTURA RESIDENCIAL EN LA AGLOMERACIÓN URBANA MADRILEÑA}

La ciudad española ha experimentado, recientemente, una expansión del espacio urbanizado sin precedentes, que no ha venido acompañada de un crecimiento demográfico paralelo. Este nuevo modelo de ciudad ha supuesto la ruptura con el modelo me- 
tropolitano anterior, gestado desde comienzos de los años sesenta del pasado siglo, y su sintonía con algunos de los rasgos definidos en el modelo de la ciudad dispersa.

En los años del desarrollismo, la reorganización de las funciones urbanas en el espacio metropolitano de nuestras ciudades afectó, fundamentalmente, a la redistribución de su población. La construcción de polígonos de viviendas en el extrarradio constituyó, sin duda, en aquellas fechas, uno de los hitos de aquellos años que más han marcado la impronta de nuestras urbes. Las nuevas expectativas de alza en el precio de la vivienda, generadas por una demanda en creciente aumento, y la modificación de los parámetros de la estructura productiva inmobiliaria (desarrollo de la promoción privada de la vivienda, especulación del suelo, tenencia en régimen de compra, falta de control urbanístico, etc.) favorecieron la elección de las áreas suburbanas como lugar ideal donde asentar los lugares de residencia de las personas recién llegadas a la ciudad. Este modelo territorial suponía, en esencia, la presencia de un núcleo central dominante y una periferia subordinada, desprovista de toda actividad terciaria de vocación central, obligada, preferentemente, a la localización de usos industriales y residenciales. El resultado fue la conformación de áreas metropolitanas clásicas, con contrastes sociales de carácter sectorial muy marcados, donde junto a zonas residenciales de elevada densidad edificatoria, localizadas en los municipios próximos al municipio central, existían áreas de ocupación más extensiva, destinadas a albergar a la población de mayor nivel de renta. Este modelo de desarrollo, cuyo crecimiento residencial tuvo lugar a saltos (localizado en primera instancia en los municipios más cercanos a la ciudad central y, posteriormente, en los más alejados) concentró, en un limitado número de núcleos urbanos, la mayor parte del incremento demográfico de la periferia.

La crisis urbanística de los años ochenta no tardó en dejar sentir sus efectos sobre la dinámica y organización interna de la ciudad. El primero y más importante fue la crisis de la industria urbana, evidenciada en la perdida de un gran número de empleos en el sector productivo secundario, lo que ha detenido, o al menos ralentizado, desde entonces, el proceso de crecimiento demográfico, hasta entonces consustancial con el modelo metropolitano. La disminución de los ritmos de incremento de la población en nuestras grandes urbes ha contrastado (al menos hasta el comienzo de la crisis económica actual) con la gran actividad inmobiliaria del sector de la vivienda y el procedente de la relocalización de las actividades terciarias en el territorio. $\mathrm{La}$ suburbanización residencial ha tenido lugar con claro predominio de las bajas densidades y la vivienda unifamiliar. La oferta residencial en la periferia ha cambiado los tradicionales patrones locacionales, ofrecidos durante la etapa anterior, representados por actuaciones urbanísticas multifamiliares de alta densidad de ocupación del suelo. Las nuevas promociones de viviendas han sido dirigidas, mayoritariamente, a las clases sociales medias y medias altas, cuyo nivel de renta les permite, incluso, invertir en segunda y aún tercera residencia. Estos nuevos prototipos de crecimiento urbanístico han afectado, no sólo a las áreas de prestigio social elevado, que ya en la etapa anterior desarrollaron este tipo de residencia extensiva, sino a zonas de inferior estatus social, acentuando el carácter social mixto de algunas de estas áreas, debido 
a la demanda de este tipo de vivienda por parte de las clases medias y medias-bajas allí residentes.

Con objeto de verificar el proceso descrito y comparar las disparidades existentes en la aglomeración urbana madrileña, de acuerdo a las conclusiones previamente enunciadas, hemos seleccionado dos áreas de características altamente diferenciadas y contrapuestas. Por una parte, el espacio del sur de Madrid, comprendido entre las carreteras A4 y A5, que queda definida por su elevado índice de desarrollo urbano compacto. En contraste con ella, el sector oeste de la comunidad madrileña, delimitado entre las vías de comunicación de la A5 y A6, estructurada, sobre todo, en torno al corredor de la carretera de La Coruña, prototipo del crecimiento urbano disperso de toda la región.

\section{1. LAS BASES DE DATOS CATASTRALES Y SU APLICACIÓN EN EL ESTUDIO URBANO MADRILEÑO}

El principal interés de nuestra investigación es, por tanto, el de comprobar y cuantificar el proceso previamente descrito, válido para el espacio geográfico de la Comunidad de Madrid. Para ello, la utilización de las bases de datos cartográficas del catastro va a servirnos para medir algunos de los principales parámetros de este modelo de desarrollo residencial, a partir la información detallada contenida en las mismas. El catastro se organiza a partir de la parcela catastral, como unidad básica de gestión, definida como "el terreno cerrado por una línea poligonal que delimita el ámbito espacial del derecho de propiedad de un propietario o de varios proindiviso" (Guimet Pereña, 2003). Es, por tanto, la unidad de tratamiento fundamental a la que se refieren los datos catastrales. Cada parcela se identifica, obligatoriamente, de forma unívoca, por una única referencia catastral ${ }^{1}$.

La utilización de la parcela catastral en los estudios urbanos encuentra su justificación en constituir un ente geográfico homogéneo, cuya naturaleza intrínseca se deriva de su particular relación con la propiedad, así como de su contenido, relativo a sus características morfológicas, temporales y funcionales. Los datos temáticos que contienen dichas unidades espaciales de referencia pueden agruparse en diferentes tipos de variables (Sobral García, 1994):

- Variables de tipo físico, que atienden a las dimensiones de las parcelas y vienen dadas por los datos relativos a la superficie del solar y tipo de parcela:

- Superficie de la finca o parcela catastral.

- Variables morfológicas, que relacionan la parcela con su edificación, siendo los datos que pueden incluirse en esta categoría las siguientes:

\footnotetext{
${ }^{1}$ La referencia catastral de una parcela está formada por 14 caracteres. Los siete primeros son dígitos que se calculan a partir de las coordenadas UTM de su centroide, y los siete siguientes identifican la hoja de la cartografía catastral del municipio en que aquella se encuentra. Los distintos bienes inmuebles contenidos en una parcela tienen una referencia catastral individualizada, que se obtiene añadiendo a los catorce caracteres anteriores otros seis, cuatro para su numeración correlativa y dos reservados como caracteres de control.
} 
o Superficie construida total, igual a la suma de las superficies de los elementos constructivos de la finca (incluida la que corresponde imputar de sus porches y terrazas), diferenciada en construida sobre rasante, construida bajo rasante y cubierta.

- Variables temporales, que reflejan el momento de construcción de cada parcela, definido por el año de comienzo y el de finalización.

- Variables de tipo funcional, que responden al uso y destino de la edificación, de forma diferenciada para cada tipo de construcción ${ }^{2}$.

Por este motivo, la parcela catastral se ha convertido en un elemento importante para el estudio e interpretación de la ciudad, al permitir relacionar su crecimiento con la estructura y morfología urbanas connaturales con el mismo.

Con objeto de realizar el trabajo de investigación descrito, hemos utilizado la cartografía catastral urbana de los municipios metropolitanos del $\operatorname{sur}^{3}$ y oeste madri- $^{4}$ leños. La representación cartográfica de ambos conjuntos puede apreciarse en las figuras 2 y 3 , enmarcada su situación respecto a las principales vías de comunicación por carretera de la región.

Figura 2. Parcelas catastrales de la aglomeración urbana del sur madrileño

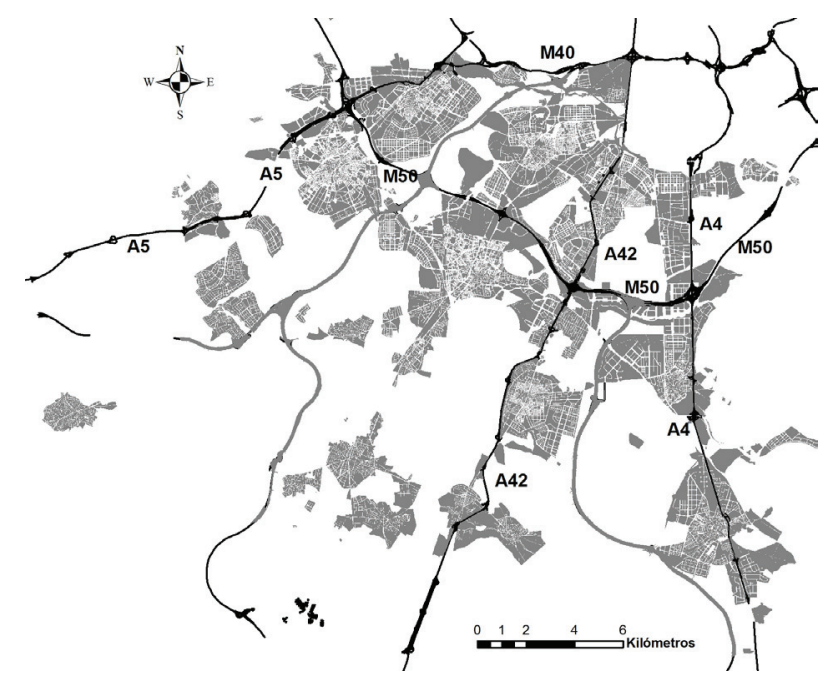

${ }^{2}$ Las categorías identificadas son las siguientes: Almacén-Estacionamiento; Residencial; Industrial; Oficinas; Comercial; Deportivo; Espectáculos; Ocio y Hostelería; Sanidad y Beneficencia; Cultural; Religioso; Obras de urbanización y jardinería; Suelos sin edificar; Edificio singular; Almacén agrario; Industrial agrario; Agrario.

${ }^{3}$ Los municipios del sur de Madrid considerados han sido: Alcorcón, Arroyomolinos, Cubas, El Álamo, Fuenlabrada, Getafe, Griñón, Humanes, Leganés, Moraleja de Enmedio, Móstoles, Parla, Pinto, Torrejón de la Calzada, Torrejón de Velasco y Valdemoro.

${ }^{4}$ Los municipios del oeste de Madrid considerados han sido: Boadilla del Monte, Brunete, Collado Villaba, Collado Mediano, Colmenarejo, El Escorial, Galapagar, Guadarrama, Las Rozas, Majadahonda, Pozuelo de Alarcón, San Lorenzo del Escorial, Torrelodones, Valdemorillo, Villanueva de la Cañada, Villanueva del Pardillo y Villaviciosa de Odón. 
Figura 3. Parcelas catastrales de la aglomeración urbana del oeste madrileño

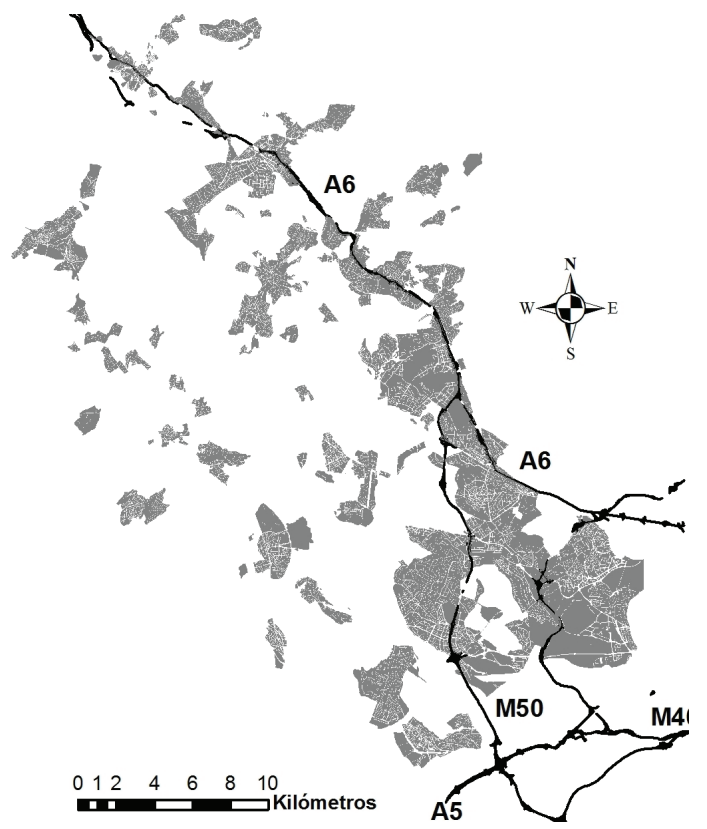

3. 1. 1. Definición DE LAS BaSES DE DATOS CATASTRALES RESIDENCIALES EN EL ANÁLisis DEL DESARROLlo DE LA ESTRUCTURA RESIDENCIAL DE MADRID, EN UN ENTORNO SIG

La posibilidad de manipular la información espacialmente referenciada, en formato digital, ha supuesto una disminución del tiempo de gestión del territorio, respecto a la utilización tradicional de soportes analógicos, lo cual sitúa a los Sistemas de Información Geográfica (SIG) en una posición de ventaja clara en el manejo eficiente de los recursos. La gestión del catastro utiliza información georreferenciada en formato "shapefile", relativa a unidades espaciales superficiales, entre ellas las parcelas ${ }^{5}$. Las bases de datos temáticas con la información literal sobre atributos y sus características añaden a las bases de datos cartográficas digitales las variables y características literales de los elementos espaciales. El enlace entre la información alfanumérica y la información gráfica se realiza a través de la referencia catastral.

Disponer de los datos geográficos (espaciales y temáticos), almacenados estructuralmente en el seno de de una base de datos, aporta una gran flexibilidad en el uso que pueda hacerse de ellos. Este uso va más allá de la producción cartográfica e incluye determinadas labores de análisis, de gran interés en la toma

${ }^{5}$ Estos recintos se almacenan como poligonales cerradas, formadas por cadenas de vértices almacenados en forma de coordenadas X, Y, utilizando como sistema de proyección UTM (proyección Universal Transversa de Mercator) y expresadas en metros. 
de decisiones espaciales. En este sentido, dichas bases de datos, vinculadas a su manejo por los SIG, nos ha permitido la posibilidad de extraer nueva información por reelaboración de la ya existente. Esta nueva información ha supuesto la selección exclusiva de las parcelas residenciales y la identificación del número de bienes inmuebles o viviendas de cada parcela ${ }^{6}$. Las variables disponibles para cada una de estas unidades espaciales, que nos servirán de base en el estudio propuesto son:

- Superficie de parcela (metros cuadrados).

- Número de viviendas por parcela.

- Superficie construida por vivienda (metros cuadrados).

- Año de finalización de la construcción de las viviendas de cada parcela.

La distribución espacial de las parcelas residenciales, correspondientes al sur y oeste madrileño vienen representadas en las figuras 4 y 5 .

Figura 4. Parcelas catastrales residenciales de la aglomeración urbana del sur madrileño

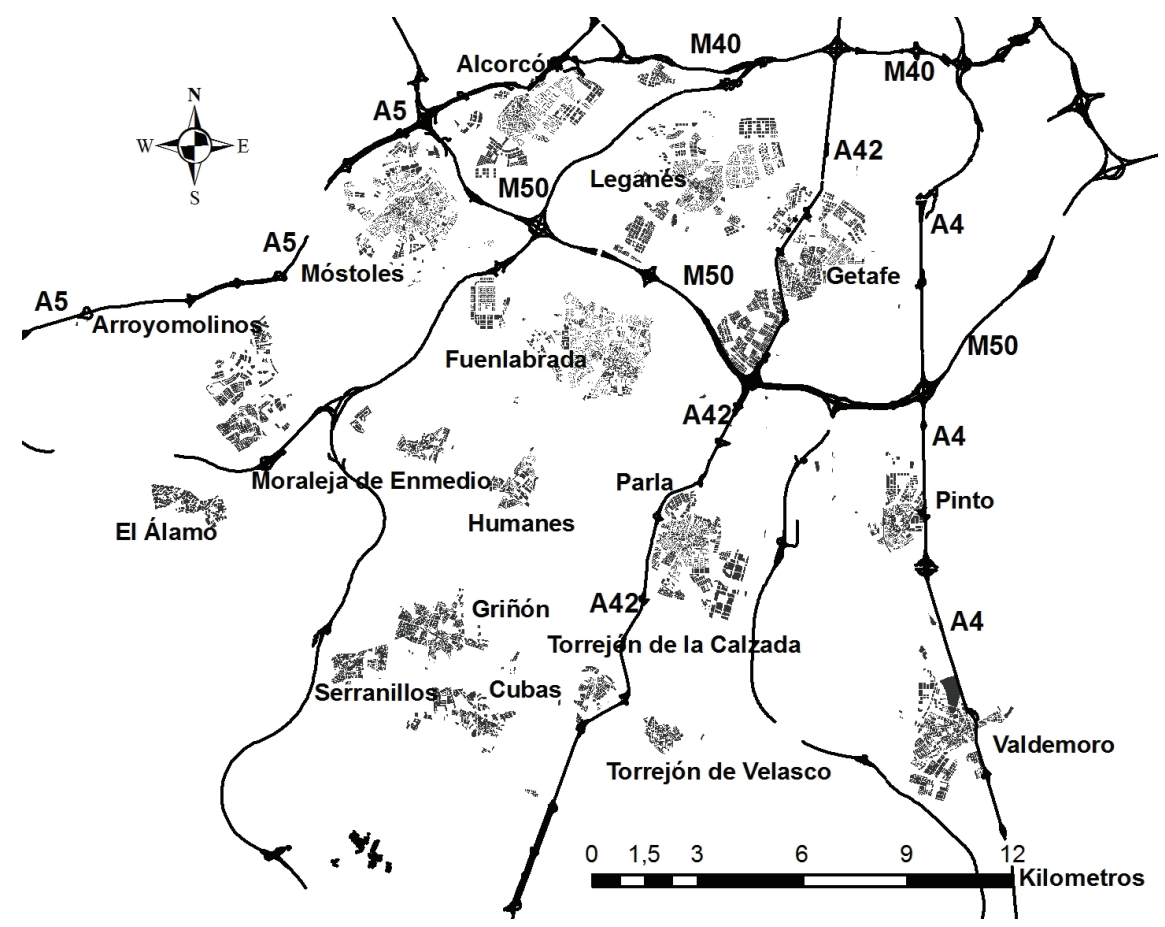

${ }^{6}$ El número de parcelas residenciales resultante ha sido, respectivamente, de 53.662 y 126.060 para el sur y oeste madrileño, con un número de viviendas correlativo de 454.223 y 304.514 . 
Figura 5. Parcelas catastrales residenciales de la aglomeración urbana del oeste madrileño

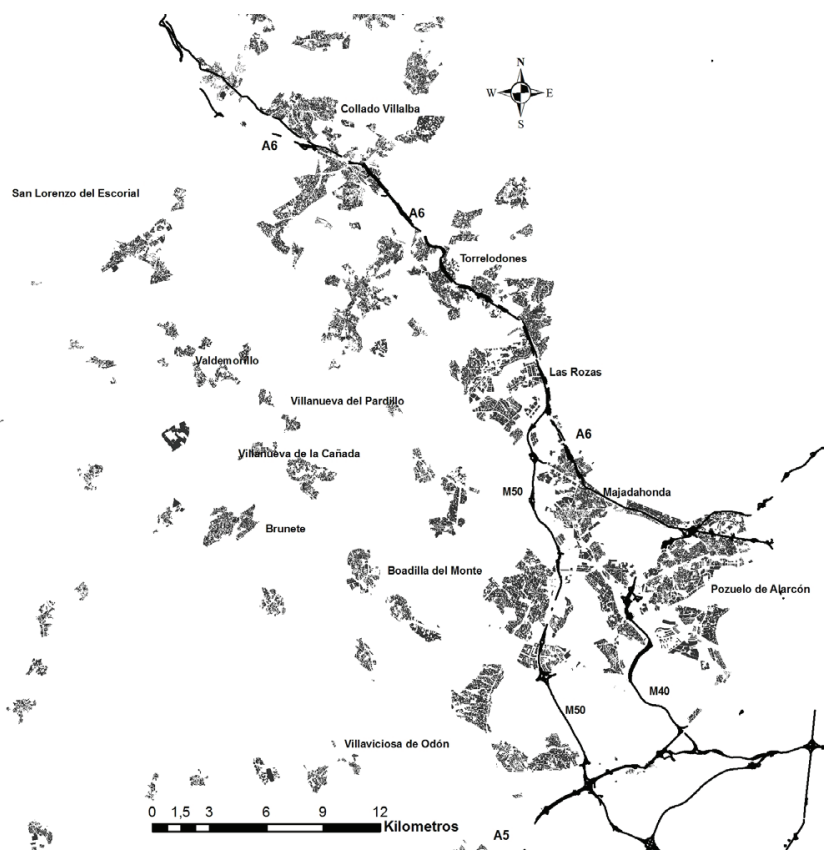

\section{2. CUANTIFICACIÓN DEL PROCESO DE CONFORMACIÓN METROPOLITANO MADRILEÑO: CONTRASTES DE LA DISPERSIÓN RESIDENCIAL ENTRE LOS SECTORES SUR Y OESTE}

La aglomeración urbana madrileña se ha convertido en un excelente banco de pruebas donde comprobar la transformación de la estructura residencial de nuestro país, de acuerdo a las nuevas pautas inherentes a la ciudad dispersa. Ello por dos motivos fundamentales. En primer lugar, por constituir el espacio geográfico madrileño un ejemplo evidente del paso de una metrópoli clásica a una metrópoli postfordista. En segundo lugar, por existir contrastes sectoriales manifiestos que permiten definir, comparativamente, el grado o nivel alcanzado por el fenómeno de la dispersión.

\section{2. 1. Resultados GLOBALES DEL PROCESO DE TRANSFORMACIÓN}

Con el fin de exponer el carácter disperso o compacto de la estructura urbana madrileña, en el proceso de transformación de la misma, desde el modelo metropolitano tradicional al modelo de ciudad disperso, hemos medido, de manera diferencial para el conjunto de los dos sectores metropolitanos indicados, la evolución temporal del crecimiento del parque de viviendas actual, mostrando los resultados globalmente 
(figura 6), o por la estructura de su tamaño ${ }^{7}$ (figura 7 y Tabla 1). En este sentido, hemos definido, en un primer momento, los intervalos para el desarrollo temporal en periodos de cinco años y la estructura de tamaño por viviendas de cada parcela:

\section{- Desarrollo temporal}

o Antes de 1965.

○ Entre 1965 y 1970.

○ Entre 1971 y 1975.

o Entre 1976 y 1980.

o Entre 1981 y 1985.

o Entre 1986 y 1990.

○ Entre 1991 y 1995.

o Entre 1996 y 2000.

○ Entre 2001 y 2005.

○ Entre 2006 y 2010.

- Estructura de tamaño de parcela por viviendas

○ Una vivienda.

○ Entre 2 y 10 viviendas.

$\circ$ Entre 11 y 20 viviendas.

o Entre 21 y 50 viviendas.

○ Más de 50 viviendas.

Figura 6. Evolución del número total de viviendas construidas en los sectores oeste y sur de la aglomeración urbana madrileña

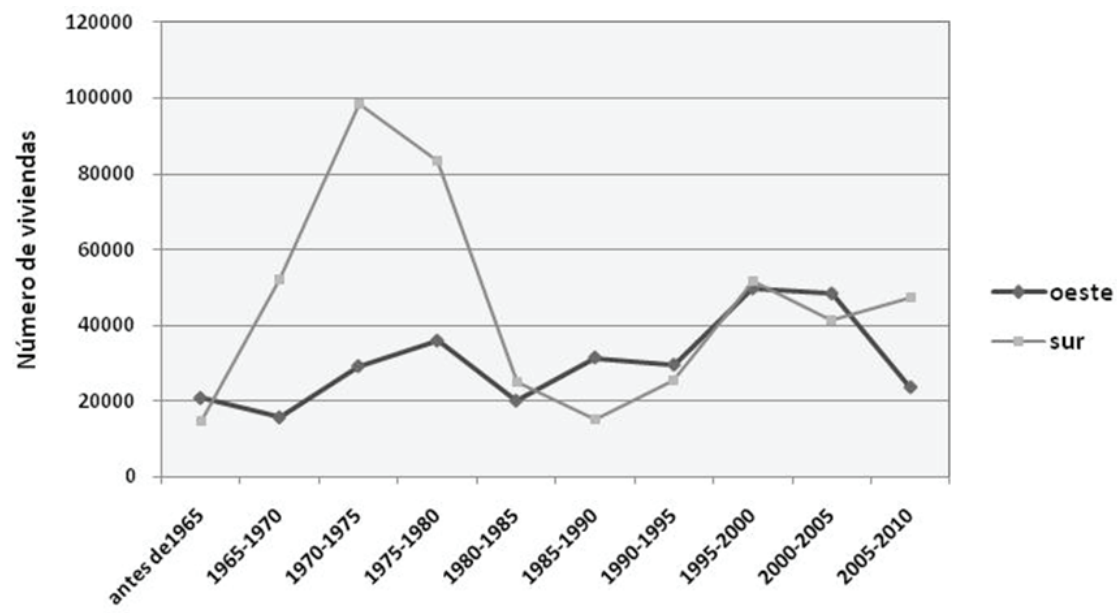

${ }^{7}$ La operación ha sido realizada, utilizando el paquete de programas estadísticos Statgraphics, tras la agrupación previa, en dos ficheros diferenciados (para cada uno de los dos sectores metropolitanos), de los registros contenidos en las tablas dBase de los municipios que las integran. Ha consistido la misma en obtener la distribución de frecuencias, relativas al número de viviendas construidas, de acuerdo a la evolución temporal y el número de viviendas por parcela. 
Figura 7. Estructura del número total de viviendas construidas según tamaño de parcela catastral, en los sectores oeste y sur de la aglomeración urbana madrileña

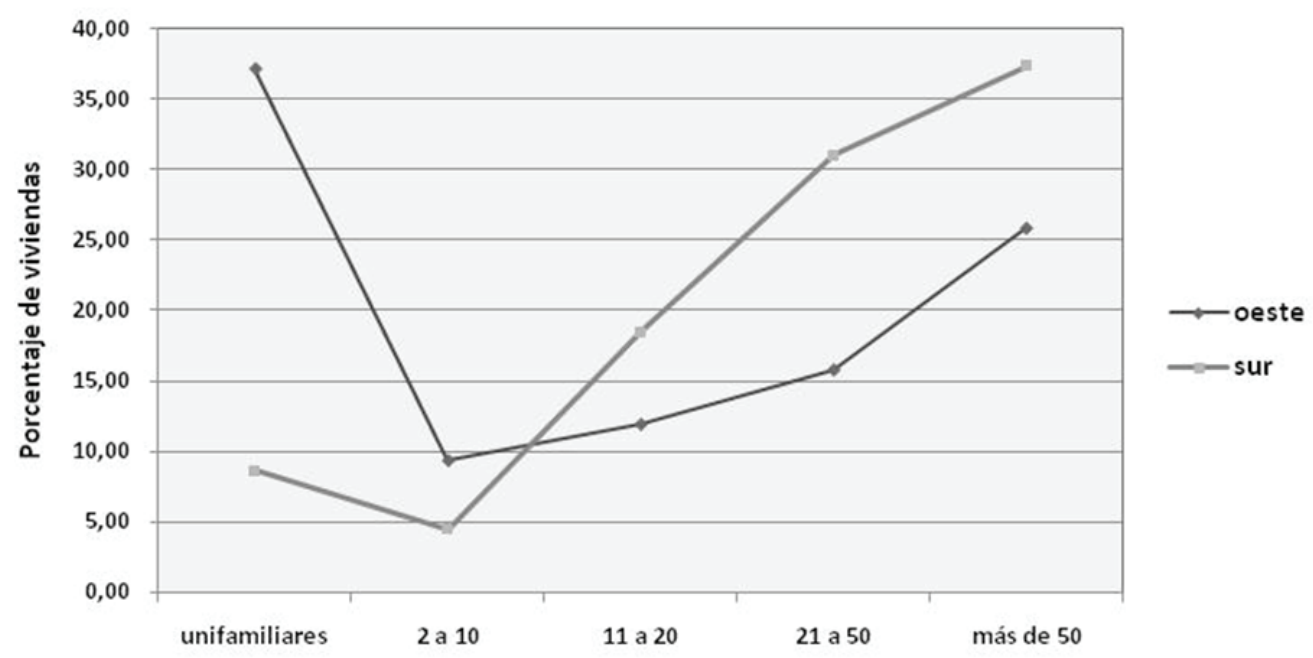

Tabla 1. Distribución porcentual de las viviendas construidas, en los sectores oeste y sur de la aglomeración urbana madrileña, según su evolución y tamaño de parcela catastral

\begin{tabular}{|c|c|c|c|c|c|c|c|}
\hline \multicolumn{8}{|c|}{ SEC TOR SUR } \\
\hline & unifamiliares & 2 a 10 & 11 a 20 & 21 a 50 & más de 50 & total & $\begin{array}{c}\text { Total } \\
\text { viviendas }\end{array}$ \\
\hline antes de1965 & 19,39 & 22,22 & 32,30 & 19,69 & 6,40 & 100,00 & 14.866 \\
\hline $1966-1970$ & 2,10 & 7,17 & 40,22 & 27,73 & 22,78 & 100,00 & 51.976 \\
\hline $1971-1975$ & 0,62 & 3,31 & 29,75 & 38,54 & 27,78 & 100,00 & 98.626 \\
\hline $1976-1980$ & 1,31 & 2,27 & 19,64 & 50,60 & 26,17 & 100,00 & 83.348 \\
\hline $1981-1985$ & 17,34 & 2,35 & 10,03 & 49,28 & 21,00 & 100,00 & 25.052 \\
\hline $1986-1990$ & 23,63 & 4,68 & 11,71 & 32,18 & 27,81 & 100,00 & 15.119 \\
\hline 1991-1995 & 17,65 & 4,73 & 9,31 & 25,46 & 42,84 & 100,00 & 25.331 \\
\hline $1996-2000$ & 15,96 & 3,53 & 3,75 & 14,89 & 61,87 & 100,00 & 51.504 \\
\hline 2001-2005 & 21,42 & 5,23 & 5,19 & 15,56 & 52,60 & 100,00 & 41.170 \\
\hline 2006-2010 & 8,71 & 3,58 & 4,00 & 12,02 & 71,68 & 100,00 & 47.231 \\
\hline total & 8,63 & 4,48 & 18,50 & 31,03 & 37,36 & 100,00 & 454.223 \\
\hline
\end{tabular}




\begin{tabular}{|c|rrrrrr|r|}
\hline \hline & SECTOR OESTE & & & \\
\hline & mifamiliares & 2 a 10 & 11 a 20 & 21 a 50 & más de 50 & Total (96) & $\begin{array}{c}\text { Total } \\
\text { viviendas }\end{array}$ \\
\hline antes de1965 & 63,34 & 19,96 & 7,63 & 4,25 & 4,82 & 100,00 & 20.804 \\
$\mathbf{1 9 6 6 - 1 9 7 0}$ & 41,91 & 17,49 & 17,15 & 19,73 & 3,72 & 100,00 & 15.681 \\
$\mathbf{1 9 7 1 - 1 9 7 5}$ & 28,74 & 10,11 & 24,42 & 16,66 & 20,07 & 100,00 & 29.210 \\
$\mathbf{1 9 7 6 - 1 9 8 0}$ & 37,47 & 11,86 & 16,46 & 15,16 & 19,05 & 100,00 & 35.922 \\
$\mathbf{1 9 8 1 - 1 9 8 5}$ & 41,49 & 7,30 & 11,20 & 16,10 & 23,90 & 100,00 & 20.068 \\
$\mathbf{1 9 8 6 - 1 9 9 0}$ & 48,17 & 7,33 & 9,50 & 12,14 & 22,86 & 100,00 & 31.479 \\
$\mathbf{1 9 9 1 - 1 9 9 5}$ & 41,93 & 8,88 & 9,43 & 14,45 & 25,31 & 100,00 & 29.592 \\
$\mathbf{1 9 9 6 - 2 0 0 0}$ & 30,55 & 5,24 & 9,20 & 19,42 & 35,60 & 100,00 & 49.739 \\
$\mathbf{2 0 0 1 - 2 0 0 5}$ & 31,00 & 6,41 & 8,21 & 16,70 & 37,68 & 100,00 & 48.381 \\
$\mathbf{2 0 0 6 - 2 0 1 0}$ & 22,77 & 9,57 & 10,04 & 19,87 & 37,75 & 100,00 & 23.638 \\
\hline total & 37,13 & 9,35 & 11,91 & 15,78 & 25,82 & 100,00 & 304.514 \\
\hline \hline
\end{tabular}

Los resultados expuestos nos permiten realizar una serie de consideraciones:

- La estructura residencial, anterior a 1965, muestra el peso relativo de la vivienda unifamiliar en el parque inmobiliario entonces existente $(19,4 \%$ en el sector sur y $63,3 \%$ en el sector oeste). Este hecho se deriva de la importancia, por aquel entonces, del sector primario en los municipios del sector sur más cercanos a Madrid capital. La tipología de la vivienda era, en gran parte, rural y de baja calidad, con una o dos plantas, con patio interior, de acuerdo a las necesidades de una población centrada en las labores agrícolas. En el caso del sector oeste, la tipología unifamiliar estaba relacionada, además, con la elección de la misma por parte de la clase burguesa como lugar de residencia secundaria durante los meses de estío, lo que explica el elevado porcentaje de viviendas de tipología extensiva.

- El periodo 1965-1980 coincide con los años del desarrollismo económico, caracterizado por la consolidación del modelo residencial metropolitano, sobre la base de una ocupación intensiva del suelo suburbano, con ciudades dormitorio de alta densidad de edificación y bajo nivel de servicios urbanos, en el sector suroeste, en la retícula constituida por las ciudades dormitorio de Getafe, Leganés, Alcorcón, Fuenlabrada, Móstoles y Parla, surgida al amparo de la estructura de los núcleos rurales que rodeaban a la capital. Únicamente en este sector metropolitano, se edificaron, en este periodo de tiempo, más de 230.000 viviendas (número que supera el 50\% del parque inmobiliario actual), en operaciones urbanísticas de elevada densidad (más de 155.000 de ellas en parcelas catastrales de más de 20 viviendas y apenas el $1 \%$ en viviendas unifamiliares). La vivienda multifamiliar en bloque abierto cimentó un tipo de ciudad fragmentada, por la falta de dotaciones urbanísticas de todo tipo, e integrada, funcionalmente, a los antiguos centros de población, que actuaron como núcleos de cristalización del acelerado y desequilibrado crecimiento urbano de aquellos años. 
Este modelo compacto se produjo de manera paralela al desarrollo de suburbios residenciales de baja densidad en el oeste metropolitano (más del 35\% eran viviendas unifamiliares), en urbanizaciones de viviendas independientes, en ocasiones de segunda residencia (principalmente en la zona de la sierra), destinadas al alojamiento de las clases sociales de nivel social superior, desarrollando un tejido residencial más extensivo, aunque con un volumen de viviendas edificadas bastante inferior. Es allí, sin embargo, donde se concentraron los equipamientos y servicios urbanos de todo tipo, marcando un profundo desequilibrio territorial y una considerable segregación espacial entre ambos sectores metropolitanos.

- La crisis de los años ochenta conllevó, en la Comunidad de Madrid, un escandaloso índice de destrucción de empleo, un alto crecimiento de las tasas de paro y un saldo migratorio negativo (63.559 habitantes), consecuencia de la caída de la demanda, pero también de la sustitución de trabajo por capital e incremento de la productividad por persona ocupada (Comunidad de Madrid, 1986). El resultado más inmediato fue la ralentización de la actividad edificatoria en el sector inmobiliario, que queda reflejado en la disminución del ritmo de crecimiento de la función residencial, sobre todo en el sector sur de la Comunidad, donde el volumen de nuevas viviendas, recogidas en el catastro, quedó reducido a la cuarta parte del periodo anterior (escasamente 40.000 viviendas en esta década).

- Desde finales de la de los años ochenta, hemos asistido a la transformación de determinadas pautas que guiaron el desarrollo urbano anterior, apareciendo algunos de los rasgos definitorios del modelo de la ciudad dispersa. La promoción de vivienda unifamiliar se aceleró a un ritmo hasta entonces desconocido. La oferta de este tipo de vivienda, activada por la difusión entre la clase media de la ideología clorofílica y el crecimiento del uso del automóvil, ha modificado, o al menos diversificado, alguno de los rasgos del tradicional papel segregativo adjudicado a la periferia madrileña. Los municipios situados en la periferia oeste, lugar de la reciente expansión residencial de las clases medias madrileñas (Pozuelo de Alarcón, Torrelodones, Las Rozas de Madrid, Boadilla del Monte, Majadahonda y Villaviciosa de Odón) son los que muestran valores de crecimiento demográfico más elevado (413\% en 20 años), producto del movimiento periférico de la población de mayor nivel de renta hacia áreas de hábitat suburbano de mayor calidad ambiental, lo que explica la construcción de más de 42.000 viviendas unifamiliares en el periodo 1990-2005, únicamente en este sector de la ciudad. Constituye, en general, una zona fundamentalmente residencial, de vivienda cara, con equipamientos ligados a la calidad del entorno (campos de golf, centros universitarios, grandes centros comerciales y zonas de descentralización de oficinas de cierto prestigio). Por su parte, las áreas del sur han modificado su estatus social según la distancia a la capital. Así, los municipios más cercanos han visto revalorizar su suelo urbano, constituyendo lugares de promoción de vivienda unifamiliar de una cierta calidad (Getafe Norte, Sector III, etc.), con porcentajes que superan el $20 \%$ de este tipo de vivienda sobre el total edificado, lo que ha supuesto un contraste social importante entre los municipios de la primera y la segunda coronas metropolitanas en este sector de la ciudad.

- En el periodo comprendido entre 2000 y 2006, si bien la expansión residencial ha continuado en todas las zonas metropolitanas, ésta se ha ido ralentizando en términos relativos a medida que nos aproximamos al centro de Madrid. De esta manera, han sido los ámbitos más periféricos en los bordes del área metropolitana, como el frente serrano y el sureste de la Comunidad, los que han soportado crecimientos más 
acusados. Se trata de un proceso que responde a criterios de distancia que van aminorándose a medida que se produce la mejora de los transportes y se consolidan las primeras coronas metropolitanas. Como resultado, se han incorporado nuevas áreas residenciales en municipios hasta entonces escasamente integrados en el ámbito metropolitano, como las zonas de la Sierra Central y el entorno de la M-501, en el Oeste de la Comunidad. Hacia el sur, el dinamismo residencial también se ha generalizado, desde mediados de los noventa hasta nuestros días, en municipios cada vez más periféricos como Valdemoro, Pinto, Ciempozuelos y Humanes, que han prolongado la actividad residencial de la corona metropolitana meridional.

- Desde el año 2007, la crisis del sector de la vivienda, causada por la reciente explosión de la burbuja inmobiliaria, ha provocado una brusca caída de la demanda como consecuencia de la incapacidad del mercado para absorber la enorme oferta de vivienda construida y vacía disponible, acelerada por el constante crecimiento de los precios. Este cambio de ciclo inmobiliario, motivado por la falta de liquidez del sistema financiero y el agotamiento del modelo de crecimiento (basado en la construcción), ha paralizado la actividad residencial, circunstancia que se aprecia claramente en el fuerte descenso de nuevas viviendas en el sector oeste de la Comunidad de Madrid.

\section{2. 2. Contraste espacial De la estructura Residencial, EN LOS SECTORES SUR Y OESTE, RESPECTO A LA COMPACIDAD Y DISPERSIÓN}

El estudio de la estructura residencial de los dos sectores metropolitanos, especificado por el momento de su construcción y el tamaño de la parcela catastral urbana (medida por el número de viviendas por parcela), lo hemos completado, añadiendo un tercer elemento, relacionado con la situación de la vivienda respecto al centro de la metrópoli en su conjunto ${ }^{8}$. En general, el fenómeno de la dispersión de la edificación en el territorio metropolitano ha tenido lugar en fases, generando una estructura policéntrica, a partir de la ocupación de suelo cada vez más periférico. Este patrón residencial varía de acuerdo al momento histórico en el que se ha producido la urbanización del territorio, así como al sector de la ciudad considerado. Como ya señalamos, durante el período álgido del desarrollo metropolitano madrileño, la construcción de viviendas tuvo lugar en los ensanches más cercanos al centro urbano, en operaciones urbanísticas de alta densidad, mientras que, más recientemente, la construcción de viviendas se ha realizado bajo estándares más extensivos, con predominio de construcciones unifamiliares o de baja densidad, en áreas más alejadas del centro de la ciudad.

Con esta intención, hemos estructurado el espacio en coronas concéntricas, de acuerdo al criterio que se señala a continuación ${ }^{9}$ :

${ }^{8}$ Se ha tomado como centro de la ciudad, el centroide del espacio ocupado por la Puerta del Sol de Madrid.

${ }^{9}$ Las coronas concéntricas se han obtenido, aplicando el módulo "ArcToolbox" "Analysis Tools" "Proximity" "Multiple Ring Buffer" de ArcGIS. 


\section{- Estructura de tamaño por viviendas}

o Entre 5.000 y 10.000 metros.

$\circ$ Entre 10.000 y 15.000 metros.

$\circ$ Entre 15.000 y 20.000 metros.

○ Entre 20.000 y 25.000 metros.

○ Entre 25.000 y 30.000 metros.

$\circ$ Entre 25.000 y 30.000 metros.

$\circ$ Entre 30.000 y 35.000 metros.

○ Entre 35.000 y 40.000 metros.

○ Más de 40.000 metros.

Así mismo, de acuerdo a los resultados obtenidos en el apartado anterior hemos realizado una agrupación temporal de los primitivos intervalos, que han quedado establecidos de la siguiente manera:

\section{- Desarrollo temporal}

o Antes de 1965.

o Entre 1966 y 1975.

o Entre 1976 y 1985.

○ Entre 1986 y 2000.

○ Entre 2001 y 2010.

El cálculo de viviendas existente en cada una de las coronas, correspondiente a una tipología determinada o a un periodo de tiempo concreto, se ha realizado a partir de las herramientas disponibles en el SIG utilizado ${ }^{10}$

La estructura urbana residencial de ambos sectores, respecto a la distancia al centro de la ciudad viene recogido en las figuras 8 y 9 .

Figura 8. Estructura residencial respecto a la distancia al centro de Madrid, del sector sur de la aglomeración urbana madrileña

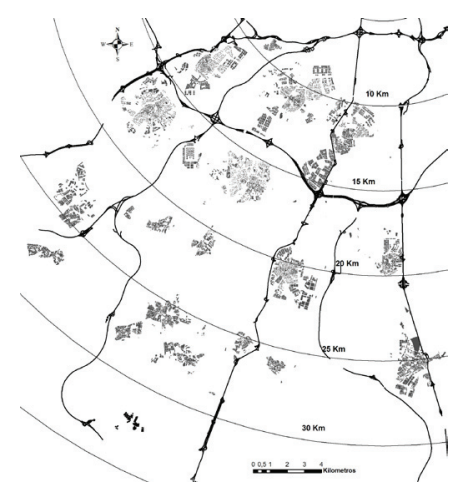

${ }^{10}$ La selección de las parcelas catastrales residenciales presentes en cada una de las coronas circulares la hemos obtenido, mediante el módulo "ArcToolbox" "Data Management Tools" "General" "Merge" de ArcGIS. El tratamiento posterior de las tablas dBase que integran su información temática, mediante el paquete de programas estadísticos Statgraphics, ha consistido en calcular los índices que a continuación se indican y analizar su valor relativo al número de viviendas construidas, de acuerdo a la evolución temporal y estructura espacial, en ambos sectores metropolitanos. 
Figura 9. Estructura residencial respecto a la distancia al centro de Madrid, del sector oeste de la aglomeración urbana madrileña

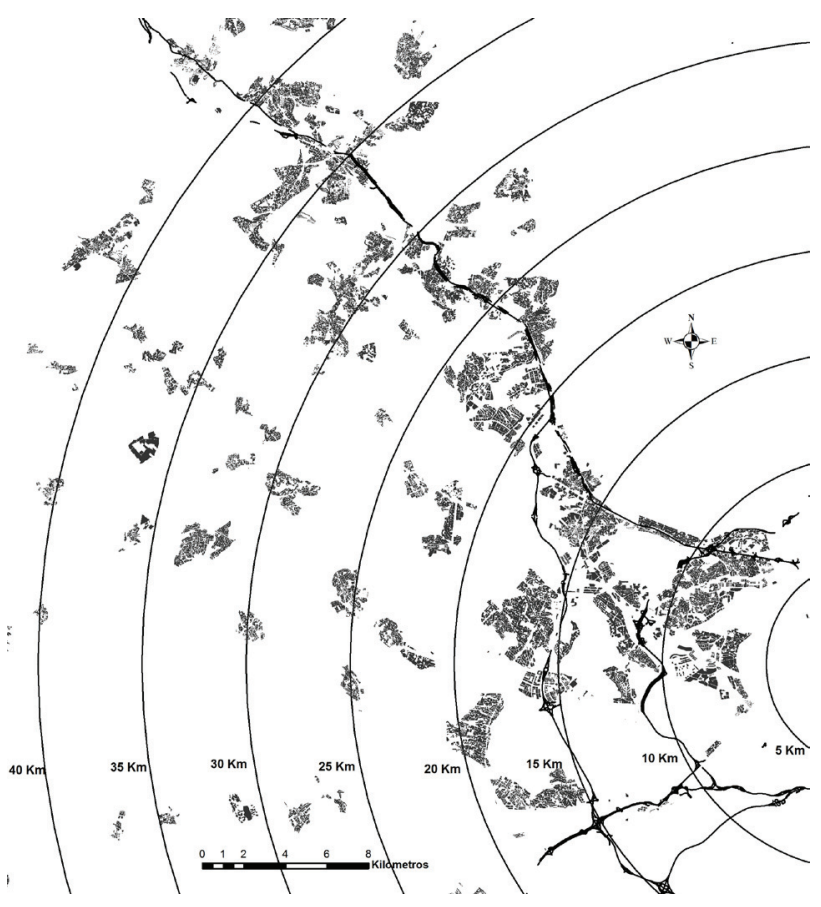

Con objeto de poder comparar el resultado alcanzado por la compacidad o dispersión del tejido residencial de ambos sectores, hemos tomado como referencia dos variables fundamentales, relacionadas con la presencia de la tipología unifamiliar y la densidad de ocupación del suelo, medida esta última por la densidad de viviendas por unidad de superficie ${ }^{11}$.

Con esta intención, hemos seleccionado y posteriormente calculado, de manera diferenciada para cada sector metropolitano (sur y oeste), de acuerdo a los intervalos de tiempo definidos y distancia al centro de la metrópoli, un conjunto de índices que sirven para medir el grado de acercamiento o alejamiento, respecto al binomio dispersión-compacidad, de su estructura urbana:

- Distribución porcentual del total de las viviendas unifamiliares, respecto a la distancia al centro, para cada intervalo de tiempo.

- Porcentaje de viviendas unifamiliares respecto al total de viviendas construidas.

- Tamaño medio del número de viviendas por parcela.

- Promedio de la superficie construida por vivienda unifamiliar $\left(\mathrm{m}^{2}\right)$.

${ }^{11}$ No hemos realizado la medición de la fragmentación del tejido residencial, que podría ser objeto de otro trabajo de investigación. 
- Promedio de la superficie construida por vivienda (resto de viviendas no unifamiliares) $\left(\mathrm{m}^{2}\right)$.

- Promedio de la superficie de parcela destinada a cada vivienda unifamiliar $\left(\mathrm{m}^{2}\right)$.

- Promedio de la superficie de parcela por vivienda (resto de viviendas no unifamiliares) $\left(\mathrm{m}^{2}\right)$.

Los dos primeros índices sirven para evaluar el peso del tejido residencial extensivo, representado por la vivienda unifamiliar, respecto al resto de urbanizaciones cuya tipología sea multifamiliar. El tercer índice refleja, al margen de la tipología, el nivel de concentración de viviendas por parcela catastral, que se relaciona, en general, con la mayor o menor densificación residencial por unidad de superficie y con las operaciones urbanísticas de mayor magnitud.

El resto de los índices calculados expresan el tamaño medio de la superficie construida y de parcela de cada vivienda, lo que supone una forma de medir el grado de dispersión-compacidad, como consecuencia de una mayor o menor ocupación del suelo por vivienda construida.

Los valores obtenidos en las tablas 2, 3, 4 y 5 nos permiten realizar una serie de reflexiones sobre la evolución de la ciudad en general y sobre los contrastes sectoriales (sur/oeste) en particular:

- La distribución de la vivienda unifamiliar, en los dos sectores analizados de la Comunidad de Madrid, muestra la progresiva implantación del tejido residencial extensivo con el paso de los años. Esta evolución, medida por el porcentaje de este tipo de viviendas respecto al total construidas, ha tenido lugar de manera más gradual en el sector oeste (del 33,2\% en el periodo 1966-1975 al 45,2\% en el periodo 2000-2010) que el sector sur (del 1,1\% al 19,7\%, respectivamente).

- La estructura espacial de la vivienda refleja que, en el sector oeste madrileño, la distribución residencial de baja densidad, respecto a la vivienda multifamiliar, ha estado bien representada por todo el territorio (el porcentaje de vivienda unifamiliar respecto al total construido no muestra una tendencia geográfica definida, aunque los valores son elevados en todas las coronas), mientras que en el sector sur, únicamente la corona más lejana (más de $25 \mathrm{Km}$ del centro de la metrópoli) concentra un porcentaje de viviendas unifamiliares representativo (aproximadamente el 50\% del total).

- Los datos globales residenciales muestran dos territorios de características altamente contrastadas. Así, mientras que, en el sur, el porcentaje de viviendas unifamiliares representa, exclusivamente, el $4 \%$ del total edificado, en el oeste, dicho porcentaje queda multiplicado por diez $(39,7 \%)$. Esta situación se refleja, igualmente, en el tamaño medio del número de viviendas por parcela catastral $(13,2$ en el sur por 2,3 en el oeste).

- En general, el tamaño medio de superficie construida de la vivienda unifamiliar es superior en el sector oeste $\left(271,6 \mathrm{~m}^{2}\right)$, que en el sector sur $\left(232,2 \mathrm{~m}^{2}\right)$. Pensamos que este hecho es la consecuencia de una mejor calidad residencial, que se pone, sobre todo, de manifiesto, si comparamos el tamaño medio de parcela $\left(804,6 \mathrm{~m}^{2}\right.$ del oeste frente a $285,7 \mathrm{~m}^{2}$ del sur). Aunque no hemos realizado un estudio detallado sobre la morfología residencial, el sector oeste destaca por la mayor presencia de viviendas aisladas frente a la tipología clásica de los adosados del sector sur (figura 10). 
Figura 10. Morfología urbana de urbanizaciones residenciales (Las Rozas y Getafe)

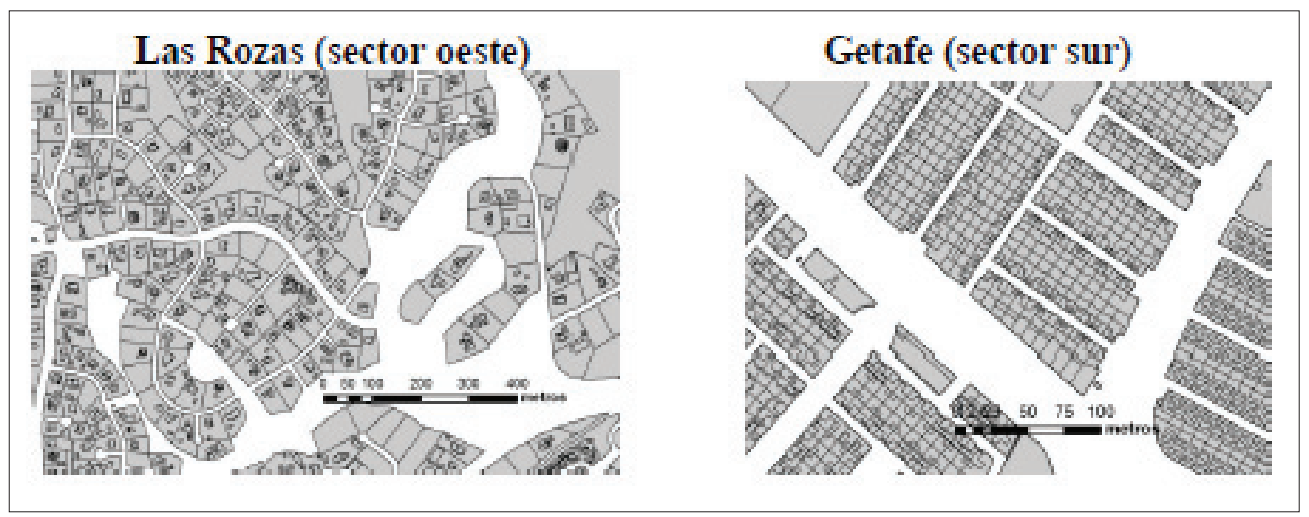

- El tamaño medio de superficie construida de la vivienda unifamiliar ha ido incrementándose con el paso del tiempo en el sector oeste metropolitano $\left(264,2 \mathrm{~m}^{2}\right.$ a 290,0 $\left.\mathrm{m}^{2}\right)$, circunstancia que no se aprecia en el sur $\left(256,4 \mathrm{~m}^{2}\right.$ a $\left.242,4 \mathrm{~m}^{2}\right)$. Dicha tendencia no se mantiene en el caso del tamaño medio de la parcela que, en general, ha disminuido en ambos casos $\left(573,5 \mathrm{~m}^{2}\right.$ a $251,2 \mathrm{~m}^{2}$ en el sur y $1.020,6 \mathrm{~m}^{2}$ a $660,3 \mathrm{~m}^{2}$ en el oeste).

- Respecto a la estructura espacial, en el sector oeste se aprecia un mayor tamaño de vivienda y de superficie de parcela en las viviendas más cercanas al centro de la ciudad $\left(398,5 \mathrm{~m}^{2}\right.$, entre 10 y $15 \mathrm{Km}$, frente a $220,6 \mathrm{~m}^{2}$ a más de $40 \mathrm{Km}$, en el primer caso y $1211,7 \mathrm{~m}^{2}$ y $696,5 \mathrm{~m}^{2}$, en el segundo). Este hecho tiene que ver, seguramente, con la calidad de la vivienda de determinados municipios como Majadahonda, Pozuelo de Alarcón y Las Rozas, localizados a mayor proximidad de la capital, respecto a los municipios de la sierra. Estas pautas no son aplicables al sector sur de la ciudad, que invierten la tendencia, sobre todo en lo que se refiere al tamaño de parcela, de 194,4 $\mathrm{m}^{2}$, entre 10 y $15 \mathrm{Km}$, a $408,5 \mathrm{~m}^{2}$ a más de $25 \mathrm{Km}$.

- Por su parte, la vivienda multifamiliar ha seguido pautas algo diferenciadas respecto a la unifamiliar. El tamaño medio de superficie construida y de parcela ha progresado, en ambos sectores urbanos, de manera similar, hacia una mayor magnitud con el paso de los años. Así, en el sector sur, el tamaño medio ha pasado de $116,9 \mathrm{~m}^{2} \mathrm{y} 104,3 \mathrm{~m}^{2}$, respectivamente, a $139,6 \mathrm{~m}^{2}$ y $253,0 \mathrm{~m}^{2}$, en idénticos periodos de tiempo, mientras que en el sector oeste lo hacía de $98,0 \mathrm{~m}^{2}$ y $69,8 \mathrm{~m}^{2}$ a $145,2 \mathrm{~m}^{2}$ y $126,3 \mathrm{~m}^{2}$.

- Finalmente, respecto a la estructura espacial de la vivienda multifamiliar, los dos sectores han evolucionado, sin embargo, de manera diferenciada. Así, mientras que en el sector sur, el tamaño medio ha crecido con la distancia al centro de la ciudad, pasando de $120,2 \mathrm{~m}^{2}$ y $86,8 \mathrm{~m}^{2}$, respectivamente, a $135,4 \mathrm{~m}^{2}$ y $278,9 \mathrm{~m}^{2}$, el sector oeste lo hacía disminuyendo los mismos, de $163,5 \mathrm{~m}^{2}$ y $132,5 \mathrm{~m}^{2}$ a $104,3 \mathrm{~m}^{2}$ y $88,6 \mathrm{~m}^{2}$. 
Tabla 2. Valor de la distribución porcentual de vivienda unifamiliar, porcentaje de unifamiliares respecto al total de viviendas construidas y tamaño medio de vivienda por parcela, de acuerdo con la distancia al centro de la metrópoli e intervalo de tiempo de construcción, en el sector sur de la aglomeración urbana de Madrid

\begin{tabular}{|c|c|c|c|c|c|c|}
\hline \multicolumn{7}{|c|}{ SECTOR SUR } \\
\hline \multicolumn{7}{|c|}{ Distribución porcentual de las unifamiliares } \\
\hline \multirow{2}{*}{$\begin{array}{c}\text { Distancia } \\
\text { (lialómetros) }\end{array}$} & \multicolumn{6}{|c|}{ Año de construcción } \\
\hline & $\begin{array}{c}\text { antes de } \\
1965\end{array}$ & $1966-1975$ & $1976-1985$ & $1986-2000$ & $2001-2010$ & total \\
\hline menos de 10 & 1,2 & 2,1 & 0,6 & 0,1 & 0,1 & 0,4 \\
\hline 10 a 15 & 23,6 & 14,9 & 7,0 & 68,8 & 62,4 & 49,5 \\
\hline 15 a 20 & 33,9 & 15,2 & 7,4 & 4,5 & 17,5 & 15,2 \\
\hline 20 a 25 & 20,3 & 23,3 & 24,1 & 6,3 & 7,4 & 11,8 \\
\hline 25 a 30 & 21,1 & 44,5 & 60,9 & 20,3 & 12,8 & 23,0 \\
\hline 30 a 35 & - & - & - & - & - & - \\
\hline 35 a 40 & - & - & - & - & - & - \\
\hline más de 40 & - & & - & - & - & - \\
\hline total & 100,0 & 100,0 & 100,0 & 100,0 & 100,0 & 100,0 \\
\hline \multicolumn{7}{|c|}{ Porcentaje de unifamiliares respecto al total de viviendas } \\
\hline \multirow{2}{*}{$\begin{array}{c}\text { Distancia } \\
\text { (lilómetros) }\end{array}$} & \multicolumn{6}{|c|}{ Anio de construcción } \\
\hline & $\begin{array}{c}\text { antes de } \\
1965\end{array}$ & $1966-975$ & $1976-1985$ & $1986-2000$ & 2001-2010 & total \\
\hline menos de 10 & 3,0 & 0,3 & $\overline{0,1}$ & 0,1 & 0,1 & 0,3 \\
\hline 10 a 15 & 6,5 & 0,3 & 0,2 & 18,7 & 51,5 & 5,1 \\
\hline 15 a 20 & 55,1 & 0,6 & 0,1 & 0,4 & 6,5 & 1,4 \\
\hline 20 a 25 & 66,7 & 4,3 & 2,4 & 2,5 & 15,7 & 5,2 \\
\hline 25 a 30 & 86,2 & 54,2 & 36,9 & 40,5 & 67,5 & 49,4 \\
\hline 30 a 35 & - & - & - & - & - & - \\
\hline 35 a 40 & - & - & - & - & - & - \\
\hline más de 40 & - & - & - & - & - & - \\
\hline total & 19,4 & 1,1 & 0,9 & 5,0 & 19,7 & 4,0 \\
\hline \multicolumn{7}{|c|}{ Tamaño medio del número de viviendas por parcela } \\
\hline \multirow{2}{*}{$\begin{array}{c}\text { Distancia } \\
\text { (lilómetros) }\end{array}$} & \multicolumn{6}{|c|}{ Año de construcción } \\
\hline & $\begin{array}{c}\text { antes de } \\
1965\end{array}$ & $1966-975$ & 1976-1985 & $1986-2000$ & 2001-2010 & total \\
\hline menos de 10 & 9,8 & 24,0 & 28,6 & 31,5 & 38,6 & 26,3 \\
\hline 10 a 15 & 7,4 & 24,9 & 27,4 & 4,6 & 1,9 & 11,3 \\
\hline 15 a 20 & 1,6 & 20,1 & 29,0 & 29,9 & 10,5 & 21,1 \\
\hline 20 a 25 & 1,4 & 10,7 & 15,2 & 15,4 & 5,1 & 10,6 \\
\hline 25 a 30 & 1,1 & 1,7 & 2,4 & 2,2 & 1,4 & 1,9 \\
\hline 30 a 35 & - & - & - & - & - & - \\
\hline 35 a 40 & - & - & - & - & - & - \\
\hline más de 40 & - & - & - & - & - & - \\
\hline total & 3,8 & 19,7 & 22,7 & 12,2 & 4,4 & 13,2 \\
\hline
\end{tabular}


Tabla 3. Valor de la distribución porcentual de vivienda unifamiliar, porcentaje de unifamiliares respecto al total de viviendas construidas y tamaño medio de vivienda por parcela, de acuerdo con la distancia al centro de la metrópoli e intervalo de tiempo de construcción, en el sector oeste de la aglomeración urbana de Madrid

\begin{tabular}{|c|c|c|c|c|c|c|}
\hline \multicolumn{7}{|c|}{$\begin{array}{l}\text { SECTOR OESTE } \\
\text { porcentual de las unifamiliares }\end{array}$} \\
\hline \multirow{2}{*}{$\begin{array}{c}\text { Distancia } \\
\text { (lilómetros) }\end{array}$} & \multicolumn{6}{|c|}{ Año de construcción } \\
\hline & $\begin{array}{c}\text { antes de } \\
1965 \\
\end{array}$ & $1966-1975$ & $1976-1985$ & $1986-2000$ & $2001-2010$ & total \\
\hline menos de 10 & 11,4 & 11,5 & 10,6 & 11,7 & 11,9 & 11,4 \\
\hline 10 a 15 & 2,8 & 7,0 & 9,8 & 8,4 & 8,2 & 7,7 \\
\hline 15 a 20 & 4,6 & 6,8 & 7,7 & 10,0 & 19,0 & 10,4 \\
\hline 20 a 25 & 4,2 & 5,2 & 6,9 & 10,2 & 12,6 & 8,4 \\
\hline 25 a 30 & 9,9 & 9,0 & 9,9 & 9,5 & 8,5 & 9,3 \\
\hline 30 a 35 & 11,7 & 10,0 & 10,6 & 10,7 & 12,5 & 11,1 \\
\hline 35 a 40 & 12,8 & 13,4 & 12,7 & 12,6 & 9,5 & 12,0 \\
\hline más de 40 & 42,7 & 37,2 & 31,9 & 27,3 & 17,8 & 29,7 \\
\hline total & 100,0 & 100,0 & 100,0 & 100,0 & 100,0 & 100,0 \\
\hline \multicolumn{7}{|c|}{ Porcentaje de unifamiliares respecto al total de viviendas } \\
\hline \multirow{2}{*}{$\begin{array}{c}\text { Distancia } \\
\text { (lilómetros) }\end{array}$} & \multicolumn{6}{|c|}{ Año de construcción } \\
\hline & $\begin{array}{c}\text { antes de } \\
1965\end{array}$ & $1966-975$ & $1976-1985$ & $1986-2000$ & $2001-2010$ & total \\
\hline menos de 10 & 39,1 & 32,7 & 30,9 & 25,8 & 29,8 & 30,4 \\
\hline 10 a 15 & 74,9 & 36,7 & 45,9 & 41,6 & 48,6 & 44,7 \\
\hline 15 a 20 & 49,9 & 18,5 & 17,6 & 22,2 & 35,3 & 25,7 \\
\hline 20 a 25 & 95,1 & 86,4 & 67,1 & 63,8 & 53,3 & 62,8 \\
\hline 25 a 30 & 87,6 & 39,3 & 37,5 & 44,5 & 57,6 & 47,2 \\
\hline 30 a 35 & 61,0 & 22,9 & 27,3 & 40,9 & 46,4 & 35,9 \\
\hline 35 a 40 & 83,1 & 26,8 & 27,1 & 43,2 & 63,2 & 38,6 \\
\hline más de 40 & 65,2 & 42,4 & 40,3 & 47,3 & 59,0 & 48,1 \\
\hline total & 63,4 & 33,2 & 33,2 & 38,5 & 45,2 & 39,7 \\
\hline \multicolumn{7}{|c|}{ Tamaño medio del número de viviendas por parcela } \\
\hline \multirow{2}{*}{$\begin{array}{c}\text { Distancia } \\
\text { (lilómetros) }\end{array}$} & \multicolumn{6}{|c|}{ Año de construcción } \\
\hline & $\begin{array}{c}\text { antes de } \\
1965\end{array}$ & $1966-975$ & $1976-1985$ & $1986-2000$ & $2001-2010$ & total \\
\hline menos de 10 & 2,2 & 2,6 & 2,9 & 3,5 & 3,0 & 2,9 \\
\hline 10 a 15 & 1,3 & 2,5 & 2,1 & 2,0 & 1,7 & 2,0 \\
\hline 15 a 20 & 1,7 & 4,4 & 4,8 & 4,0 & 2,7 & 3,5 \\
\hline 20 a 25 & 1,0 & 1,1 & 1,4 & 1,5 & 1,8 & 1,5 \\
\hline 25 a 30 & 1,1 & 2,2 & 2,3 & 2,0 & 1,6 & 1,9 \\
\hline 30 a 35 & 1,5 & 3,6 & 3,2 & 2,2 & 2,0 & 2,5 \\
\hline 35 a 40 & 1,2 & 3,2 & 3,2 & 2,1 & 1,5 & 2,3 \\
\hline más de 40 & 1,4 & 2,1 & 2,2 & 1,9 & 1,6 & 1,9 \\
\hline total & 1,4 & 2,6 & 2,7 & 2,3 & 2,1 & 2,3 \\
\hline
\end{tabular}


Tabla 4. Valor del promedio de la superficie construida por tipo de vivienda (unifamiliar y resto) $\left(\mathrm{m}^{2}\right)$, de acuerdo con la distancia al centro de la metrópoli e intervalo de tiempo de construcción, en los sectores sur y oeste de la aglomeración urbana de Madrid

\begin{tabular}{|c|c|c|c|c|c|}
\hline \multicolumn{6}{|c|}{ Promedio de la superficie construida por vivienda unifamiliar } \\
\hline $\begin{array}{c}\text { Distancia } \\
\text { (filómetros) }\end{array}$ & SUR & OESTE & $\begin{array}{c}\text { Año de } \\
\text { construcción }\end{array}$ & SUR & OESTE \\
\hline menos de 10 & 261,1 & 335,4 & antes de 1965 & 204,3 & 205,3 \\
\hline 10 a 15 & 226,5 & 398,5 & $1966-1975$ & 256,4 & 264,2 \\
\hline 15 a 20 & 224,4 & 346,4 & $1976-1985$ & 203,3 & 288,4 \\
\hline $20 \times 25$ & 234,2 & 321,9 & $1986-2000$ & 236,2 & 266,1 \\
\hline 25 a 30 & 239,7 & 268,4 & 2001-2010 & 242,4 & 290,0 \\
\hline 30 a 35 & - & 233,2 & & & \\
\hline 35 a 40 & - & 220,7 & & & \\
\hline más de 40 & - & 220,6 & & & \\
\hline total & 232,2 & 271,6 & total & 232,2 & 271,6 \\
\hline \multicolumn{6}{|c|}{ Promedio de la superficie construida (resto de viviendas) } \\
\hline $\begin{array}{c}\text { Distancia } \\
\text { (kilómetros) }\end{array}$ & SUR & OESTE & $\begin{array}{c}\text { Año de } \\
\text { construcción }\end{array}$ & SUR & OESTE \\
\hline menos de 10 & 89,1 & 155,5 & antes de 1965 & 106,7 & 91,5 \\
\hline 10 a 15 & 120,2 & 165,3 & $1966-1975$ & 116,9 & 98,0 \\
\hline 15 a 20 & 130,6 & 131,0 & $1976-1985$ & 138,4 & 134,9 \\
\hline 20 a 25 & 128,0 & 180,6 & $1986-2000$ & 137,0 & 136,3 \\
\hline 25 a 30 & 135,4 & 126,1 & 2001-2010 & 139,6 & 145,2 \\
\hline 30 a 35 & - & 106,5 & & & \\
\hline 35 a 40 & - & 108,5 & & & \\
\hline más de 40 & - & 104,3 & & & \\
\hline total & 129,1 & 125,6 & total & 129,1 & 125,6 \\
\hline
\end{tabular}

Tabla 5. Valor del promedio de la superficie de la pardela catastral por tipo de vivienda (unifamiliar y resto) $\left(\mathrm{m}^{2}\right)$, de acuerdo con la distancia al centro de la metrópoli e intervalo de tiempo de construcción, en los sectores sur y oeste de la aglomeración urbana de Madrid

\begin{tabular}{|c|c|c|c|c|c|}
\hline \multicolumn{6}{|c|}{ Promedio de la superficie de parcela por vivienda unifamiliar } \\
\hline $\begin{array}{c}\text { Distancia } \\
\text { (kilómetros) }\end{array}$ & SUR & OESTE & $\begin{array}{c}\text { Año de } \\
\text { construcción }\end{array}$ & SUR & OESTE \\
\hline menos de 10 & 226,7 & 652,6 & antes de 1965 & 300,7 & 728,8 \\
\hline 10 a 15 & 194,4 & $1.211,7$ & $1966-1975$ & 573,5 & $1.020,6$ \\
\hline 15 a 20 & 213,3 & 960,6 & $1976-1985$ & 342,7 & 896,6 \\
\hline 20 a 25 & 304,3 & $1.002,1$ & $1986-2000$ & 261,4 & 683,3 \\
\hline 25 a 30 & 408,5 & 741,5 & 2001-2010 & 251,2 & 660,3 \\
\hline 30 a 35 & & 738,1 & & & \\
\hline 35 a 40 & & 799,6 & & & \\
\hline más de 40 & & 696,5 & & & \\
\hline total & 285,7 & 804,6 & total & 285,7 & 804,6 \\
\hline \multicolumn{6}{|c|}{ Promedio de la superficie de parcela (resto de viviendas) } \\
\hline $\begin{array}{c}\text { Distancia } \\
\text { (filómetros) }\end{array}$ & SUR & OESTE & $\begin{array}{c}\text { Año de } \\
\text { construcción }\end{array}$ & SUR & OESTE \\
\hline menos de 10 & 122,5 & 131,1 & antes de 1965 & 103,3 & 89,5 \\
\hline 10 a 15 & 86,8 & 132,5 & $1966-1975$ & 104,3 & 69,8 \\
\hline 15 a 20 & 111,3 & 102,8 & $1976-1985$ & 122,7 & 108,5 \\
\hline 20 a 25 & 112,4 & 198,5 & $1986-2000$ & 212,1 & 119,4 \\
\hline 25 a 30 & 278,9 & 111,8 & $2001-2010$ & 253,0 & 126,3 \\
\hline 30 a 35 & & 67,1 & & & \\
\hline 35 a 40 & & 84,8 & & & \\
\hline más de 40 & & 88,6 & & & \\
\hline total & 178,3 & 104,3 & total & 178,3 & 104,3 \\
\hline
\end{tabular}




\section{CONCLUSIONES}

El manejo de la cartografía catastral en los estudios de base urbana, al disponer de un gran número de unidades espaciales de información, relacionadas, de manera directa, con los agentes productores del espacio de la ciudad, ha demostrado su capacidad para analizar determinados fenómenos urbanos, como la medición de la evolución del tejido residencial extensivo de una gran urbe, como la aglomeración urbana madrileña. Esta labor se ha visto, en gran manera, facilitada, al haber gestionado dicha información geográfica a través de un SIG, al permitir considerar la relación de múltiples variables, vinculadas con su morfología y funcionalidad, de una manera rápida y eficaz.

La utilización sintética de determinados índices relacionados con la distribución espacial de la vivienda unifamiliar, así como el tamaño medio del número de viviendas por parcela o el tamaño medio de la superficie construida o de parcela de la vivienda unifamiliar, diferenciada, según sector de la ciudad, año de la edificación y situación respecto a la distancia al centro de la metrópoli, nos ha posibilitado comprobar la evolución de la aglomeración urbana madrileña, desde un área metropolitana tradicional, conforme con los presupuestos de la etapa fordista, a un área urbana más acorde con algunas fundamentales de las características de la ciudad dispersa. Esta metodología ha servido, además, para poder medir los profundos contrastes existentes, respecto a la progresión del tejido residencial de baja densidad, entre los sectores del sur y oeste de la Comunidad de Madrid.

\section{BIBLIOGRAFÍA}

CAPEL, H. (2003): "Redes, chabolas y rascacielos. Las transformaciones físicas y la planificación en las áreas metropolitanas", en Arquitectura y espacio urbano, $\mathrm{n}^{\circ}$ 3, Caja Rural Intermediterránea. Instituto de Estudios Socioeconómicos de Cajamar.

CASTELLS, M. (2001): La galaxia Internet. Areté, Barcelona.

COMUNIDAD DE MADRID (1986): La influencia de la crisis económica sobre el territorio. Consejería de Ordenación del Territorio, Medio Ambiente y Vivienda.

DEMATTEIS, G. (1998): “Suburbanización y periurbanización. Ciudades anglosajonas y ciudades latinas", en La ciudad dispersa: suburbanización y nuevas periferias, F. J. Monclús (Ed). Centro de Cultura Contemporánea. Barcelona, 5-15.

DUPUY, G. (1995): Territoires de l'automobile, Anthropos-Economica, París.

ENTRENA DURÁN, F. (2004): El fenómeno de la periurbanización en Europa. Disponible en http://www.diba.es/parcsn/parcs/life/pdfs/FranciscoEntrena.pdf. Universidad de Granada. 
FERIA TORIBIO, J. M. (1999): "Nuevas periferias urbanas y planificación pública", en La ciudad: tamaño y crecimiento. III Coloquio de Geografía Urbana. Antequera (Málaga), 309-316.

FERRÁS SEXTO, C. (2000): “Ciudad dispersa, aldea virtual y revolución tecnológica. Reflexión acerca de sus relaciones y significado social”, en Scripta Nova, Revista Electrónica de Geografía y Ciencias Sociales. Disponible en http://www.ub.es/ geocrit/sn-69-68.htm. Universidad de Barcelona.

FONT, A. (2007): "Morfologías metropolitanas contemporáneas de la baja densidad", en La ciudad de la baja densidad. Lógicas, gestión y contención. F. Indovina (Coord.), Diputació de Barcelona, Colección Estudios, Serie Territorio, 97-108.

GAJA I DIAZ, F. (2004): "Evidencias e hipótesis: sobre la forma de la ciudad informacional", en CIUDAD Y TERRITORIO. Estudios Territoriales. Madrid, XXXVI, $\mathrm{n}^{\mathrm{o}}$ 141-142, 507-516.

GUIMET PEREÑA, J. (2003): Descripción y teoría general del catastro. Ediciones UPC, Barcelona.

HALL, P. (1965): The World Cities. Traducción al castellanno de Carlos Benito Cardenal, Las grandes ciudades y sus problemas, Madrid, Guadarrama.

LEÓN RODRÍGUEZ, R. (2008): Ciudades inseguras, blindaje urbano y simulacro urbanístico. Disponible en: http://www.corodebabel.com.ar/index2. php?option $=$ com_content\&do_pdf $=1 \& \mathrm{id}=51$.

MATTOS, C. (2004): Globalización y urbanización en América Latina. Instituto IAI, Ciudad de México. Disponible en http://64.233.183.104/search?q=ca che:ZV5Fyf4tRywJ:iaibr1.iai.int/SI/2004/2004UGEC_files/CD_Material/ Lunes\%2520\%252027/CM/IAI\%25202004\%2520-\%2520Temario\%2520y\%252 0bibliograf\%C3\%ADa.doc+Globalizaci\%C3\%B3n+y+urbanizaci\%C3\%B3n+en + Am $\%$ C3\%A9rica+Latina + Mattos\&hl=es\&ct $=$ clnk\&cd $=1 \& \mathrm{gl}=\mathrm{es}$

MOLINI, F y SALGADO, M. (2010): "Superficie artificial y viviendas unifamiliares en España, dentro del debate entre ciudad compacta y dispersa", en Boletín de la Asociación de Geógrafos Españoles, Madrid, nº 54, 125-147.

MUÑIZ, I., GARCÍA, M. A. y CALATAYUD, D. (2006): Sprawl. Definición, causas y efectos. Departament d'Economia Aplicada, Campus de Bellaterra, Barcelona.

SOBRAL GARCÍA, S. (1994): "La utilización del Catastro de Urbana en los trabajos de planeamiento”, I Coloquio de Geografía Urbana, Cuenca, 203-207. 